\title{
Study of the Urban and Rural Education's Fairness in the Field of Public Service
}

\author{
Yang Yang \\ Southwest University, Chongqing, China \\ Email: yangyangtangxin@vip.qq.com
}

Received November $2^{\text {nd }}, 2013$; revised December $10^{\text {th }}, 2013$; accepted December $25^{\text {th }}, 2013$

\begin{abstract}
Copyright (C) 2014 Yang Yang. This is an open access article distributed under the Creative Commons Attribution License, which permits unrestricted use, distribution, and reproduction in any medium, provided the original work is properly cited. In accordance of the Creative Commons Attribution License all Copyrights (c) 2014 are reserved for SCIRP and the owner of the intellectual property Yang Yang. All Copyright $(2014$ are guarded by law and by SCIRP as a guardian.
\end{abstract}

With the rapid economic development and social progress, the increased polarization between urban and rural areas makes the wealth gap become the resistance to block the development of state and society. The basic reason to widen the polarization of the rich and the poor is that the basic public service is not equal in urban and rural areas. And the problem of the rural-urban education's fairness is the core problem of the basic public service between urban and rural areas. So this paper is aimed at sorting out the current situation of education justice between urban and rural areas, and studying the reasons and the countermeasures of the problem.

Keywords: The Gap between Urban and Rural Areas; The Basic Public Services; The Education Equity

\section{Introduction}

To realize the socialism with Chinese characteristics, it was proposed in the Fifth Plenary Session of 16th Central Committee of CPC to a new reform proposition-the equalization of public service, and since then, specific requirements and policies around the central proposition were put forward in all meetings. It was found in the process of policy implementation that the gap between urban and rural areas has been the core factor to hinder the harmonious development. Therefore, this paper is mainly aimed at the educational justice in the field of basic public service between urban and rural areas, which is also the most difficult problem that has been bothering the government and people, and then further to explore how to promote educational fairness in rural and urban areas.

With the further development of the market economy, the unfair phenomenon is highlighted ceaselessly between urban and rural areas and it is mainly reflected in the stress surface and stress point of their public service. Our party has been exploring on the issue of balancing rural and urban development, for example, it is proposed in the 16th National Congress of the CPC that it is necessary to balance the economic and social development in urban and rural areas in order to solve the issues concerning agriculture, countryside and farmers, the country, and then the five coordinations is first is formally put forward, in which the coordination development between rural and urban is in the first place. Through the introduction and implementation of these policies, the equalization of basic public service in urban and rural areas has been greatly improved. Although the rural education has been rapidly developed, the contradictions that existed in the development process have become more and more acute, and the phenomena for education injustice become more serious especially in the Midwest areas.
The education equity means that the educational resources are distributed by the state according to the principle of rationality, which can be divided into the start fairness, the process fairness and the result fairness from the process of educational activity, their gap is not great from the current popularity rate of urban and rural compulsory education. At present, the main gap of urban and rural education mainly embodies on the quality to run a school, specifically reflected in three aspects-expenditure investment in the urban and rural education, the conditions to run a school and the level of teachers (Zhang, 2003).

Expenditure investment in the education Funds is the fundamental guarantee to effectively allocate and use the educational resources in order to ensure the realization of educational goals. The current phenomenon, such as the subject of educational funds' investment in China, is not located in right places and so on; it leads to the shortage for the migrant worker's children in the educational funds and the gap of urban and rural education will be broaden. Apart from the lack of the funds in rural compulsory education and the difficulty in providing salary for rural teachers on time, it is also a part of the educational problem in rural basic public service for ignoring the education of migrant workers' children in policy.

The conditions to run a school Although the economy keeps developing, the gap between rural and urban education in different areas is gradually widened. The rural economy in some regions rapidly develops, but there is still a large gap in the conditions to run a school between the urban and rural areas on the whole. On the one hand, it mainly reflected the lack of hardware facilities in rural areas such as the school building construction and the deficiency of multimedia equipments, yet the educational conditions in urban areas are excellent. On the other hand, the rural children' ability to perceive, being limited by the environment, is relatively weaker than that of the urban 
students. Their parents' education level is low and the rural students are not very well-informed, the rural areas are so isolated that these students can not better integrate with the society, but the education's condition of the urban students, which is affected by urbanization, is more superior to those of the rural students.

The teachers' level It is investigated that most rural teachers in middle school are relatively young. They have just graduated from school, so they lack of work experiences and need to improve their teaching capacity to meet the students' demands. In addition, their enthusiasm to work is greatly influenced by the low salary and treatment, while the middle schools in cities always do well in these aspects of the salary and treatment, and the social security.

\section{The Causes of Education Injustice between Urban and Rural Areas}

The root of the rural and urban basic education's injustice is that the institutional barrier of basic education under the urban-rural dual structure. It was caused by the interests structure's changes between the central and local government that the expenditure investment in the rural basic education is insufficient. Because there are differences in goals between the central and local government, it is difficult to determine a balance point between people's interests and the development of local economy. The stability of education is affected by the change tendency of balance point that made by the implementation subjects. And the central government's financial power is becoming stronger and stronger while the local government's financial burden is becoming heavier and heavier after implying the tax system's reform. While the rural compulsory education's expenditure mainly depends on the county government's finance, the more and more teaching requirements was meet by the local government which has to provide enough funds. All these will lead the local government to facing all heavy pressure, and because they have to face their own's harsh financial situation, the local government will not be able to guarantee the enough expenditure investment fort he rural education, which will lead to the serious differentiation between the rural and urban education.

The urban and rural differences in introducing the compulsory education system. It is regulated in the 7 Article of Compulsory Education Law of the People's Republic of China that the compulsory education should be in this system-leaded by the state council, coordinately planned and implied by the government of province, autonomous regions and municipalities, administrated mainly by the county government. Due to the economic difference all over the country, the educational gap between rural and urban areas was objectively widened to sharpen the uneven development of education.

The rural teaching quality's requirements can not be met by the limited finance. Owing to the county government have a limited financial resources and it need a large expenditure for the rural compulsory education, the hardware facilities are lagging behind in most rural schools. Many teachers would not like to come to the rural schools as the poor conditions to run a school and the low salary and treatment for them. At the same time, the rural teachers are lack of more qualification for promotion and training opportunities, it makes the teaching quality in rural areas be far inferior to that in urban areas.

The rigid household registration system is a core reason to lead the urban and rural education' injustice. The first is the education injustice caused by the shifting obstacles under the household registration system. As a result of unbalanced economic development among different regions, there is a phenomenon that people shifts from the mid-west to the eastern and coastal areas, from countryside to cities, and from the primary industry to the secondary and tertiary industry. However, their many rights for these shifted people can not be granted because it is mostly restricted in the household register system for the floating movement. Of course, it is closely related to the education problem of their children for the their floating movement. Even though it is regulated in the state policy that the local government should pay more attention to the education of migrant workers' children, who own the equal and same rights as children in cities, there are many restrictions such as high extra tuition when the urban school are recruiting the migrant worker's children.

The second is the education injustice for the phenomenon of NECC migrant under the household registration system. China starts to carry out the unified college entrance examination system after restarting the college entrance examination in 1977, but the admission number is largely based on the actual situation of different provinces, which there are uncertainty in the minimum passing score and the admission ratio. So the phenomenon is emerged that some examinees change their household registers and go on a short time migration to pursue the better education quality and opportunity, what described is NECC migrant.

\section{Measures to Achieve in the Urban and Rural Education's Fairness}

Education is one of the most important parts in the social public service, thus how to realize the rural and urban education fairness is of overwhelming importance to the equalization of social public service between the rural and urban areas.

\section{To Improve the Current Funds' Investment System and Define the Investment Subject}

Education expenditure are shared by the central and local government to optimize the financing process and perfect the system to ensure fundings. Education is the foundation for the long prosperity of a nation. The rural compulsory education, which is one of the most significant public products in rural areas, should be paid attention to its advancement by country. Therefore, we should make efforts in various aspects such as establishing a funds-investing mechanism reasonably shared by financial department of both central and local government, further strengthening the fiscal transfer payment, giving full play to the role of the government, promoting the investment system reform of rural compulsory education, defining the responsibility of government and arranging the transfer payment to the county government in accordance with the responsibility it can assume (Zhang, 2004). We can see the funding sources that construct the rural education in Figure 1. It becomes important for perfecting the investment process to ensure the accurate place of funds. The author tries to build the diagrammatic sketch for the rural education funds as follows.

Increasing the expenditure investments to improve the teaching conditions in rural schools. In order to ensure the teaching quality in rural areas, the update of teaching equipments must 


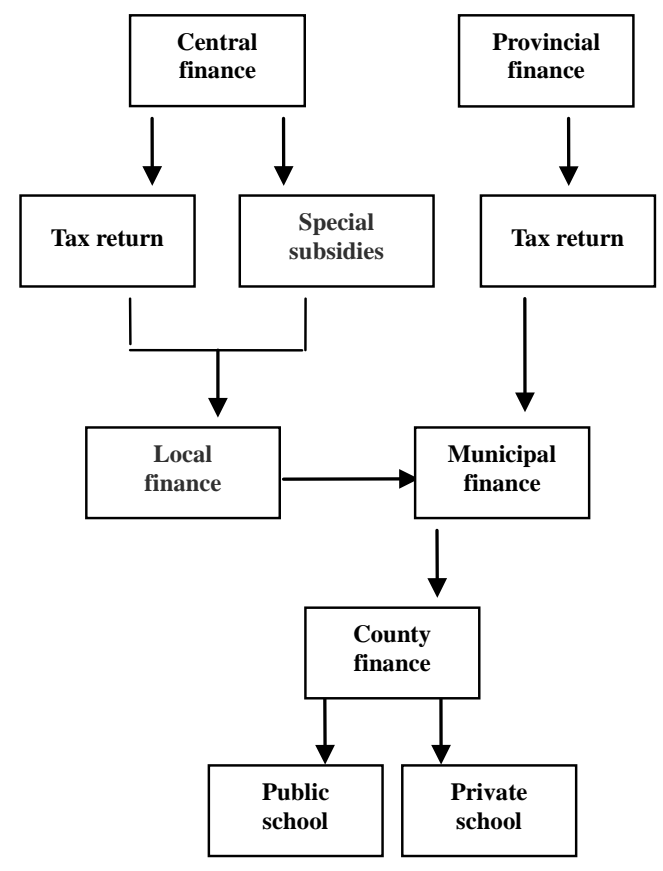

Figure 1.

The funds' sources for rural education.

keep up with the pace of urban education development. Therefore, on one hand, we ought to increase the funding investment in the hardware facilities for educational institutions in rural areas to ensure the normal use of modern equipments such as the multimedia and the laboratory. On the other hand, we need to develop the function of modern distance education project in rural elementary and middle schools to promote the high-quality education resources shared by both urban and rural schools.

\section{To Reform the Household Registration System and Cancel All Geographical Identity Limitations}

To break the restrictions of household registration, the reform of household registration system must be accelerated, the process of urban-rural integration is orderly performed and the same opportunity for rural and urban areas are provided in its system. We must balance the relationship between efficiency and fairness when the resources are allocated to overcome the urban bias in education policies and system and then truly realize the same starting line for the education development in rural and urban areas (Su, 2004). Meanwhile, it is important for us to formulate policies according to its practical situation and establish the value-orientation that the rural and urban is the same, especially in education, the same study chance should be actively provided for the rural children like the urban children by canceling the extra high fees for rural and so on. Furthermore, we ought to relatively distribute more resources to the rural areas so as to decrease the gap between urban and rural education step by step, which will not only promote the rural and urban educational fairness but realize the equalization of social public service in a real sense.

\section{To Strengthen the Construction of Teaching Staff and} Perfect Its Structure

With the problems such as the age structure and academic structure of teachers in the rural middle school, it is necessary for perfecting the teaching staff to improve the whole level and competitive power of rural schools, which can be divided into the following aspects. Firstly, the treatment of rural teachers should be improved by establishing the long-effect system in salary and treatment, introducing the performance salary that more pay more work and constructing the coordinated system of rewards and penalties that will form a competitive mechanism in the teaching team. Secondly, the relatively same level of average salary between rural and urban teachers should be ensured to further increase the working enthusiasm of urban teachers, the government must pay the salary strictly according to the related policy and provide more training chances (Fang, 2012). Thirdly, it is beneficial to encourage the rural teachers to improve their academic level by self-study examination, further study, distance education and so on. Meanwhile, according to the requirement of rural education development, we can firstly cultivate teachers who are mostly needed in certain subjects and set the relevant policies which will guide and encourage graduates to stay in rural areas and devote themselves to developing the rural education.

\section{Conclusion}

Although it keeps working hard on the education equality in rural and urban areas and has also made some achievements, the economic development and social progress should be hindered by it in our country if the education problem becomes more and more sharp. To solve the current issues, it is necessary to multilateralize coordinate and joint efforts (Feng, 2010). Firstly, the system is acted as the fundamental guarantee-institutions to improve and solve the rural and urban education problem and the implementation subject to people's livelihood project-central and local government are crucial to the amelioration of education problem in both rural and urban areas. Secondly, the educational expenditures are supported by the finance that mainly provided by local government and supplemented by the central government. The central government gives the special educational expenditures to help the rural education. Lastly, the central and local government can get together to strengthen the construction of teaching team in rural areas by perfecting policies and improving treatment $(\mathrm{Qu}$, 2010). All in all, education is the basis of social development and the degree of education justice, which is an important manifestation of social democratization process, determines the level of social development. Confronted with the situation that there is still large gap between the rich and the poor, the education is the key. We are shouldering heavier responsibility and leading a longer way to properly solve this extremely urgent education problem.

\section{REFERENCES}

Fang Changchun, Jiang Meng 方长春, 蒋萌 (2012). Huji zhidu xia de jiaoyu bu pingdeng yanjiu zongshu 户籍制度下的教育不平等研究 综述. Journal of Guizhou Social Sciences, 9, 66-69.

Feng Huimin 冯惠敏 (2010). Zhongguo gongchandang jiaoyu gongping sixiang yanjiu 中国共产党教育公平思想研究 (pp. 100-103). Wuhan: Wuhan University Press.

Qu Ying 矍瑛 (2010). Yiwu jiaoyu junheng fazhan zhengce wenti yanjiu一jiaoyu gong ping de shijiao 义务教育均衡发展政策问题 研究——教育公平的视角 (pp. 33-35). Hangzhou: Zhejiang Uni- 
YANG Y.

versity Press.

Su Junyang 苏君阳 (2004). Lun jiaoyu gongzheng de benzhi 论教育 公正的本质. Journal of Fudan Education Forum, 5, 107-109.

Zhang Aimei 张爱梅 (2003). Guanyu jiaoyu gongping de jidian sikao 关于教育公平的几点思考. Journal of Jangsu Higher Education, 1, 59-61.
Zhang Letian 张乐天 (2004). Chengxiang jiaoyu chabie de zhidu guiyin yu suoxiao chabie de zhengce jianyi 城乡教育差别的制度归 因与缩小差别的政策建议. Journal of Nanjing Normal University (Natural Science Edition), 3, 56-59. 